\title{
Effects of Nitric Oxide Exposure on Human Sperm Function and Apoptosis Markers
}

\author{
Fanuel Lampiao ${ }^{1, *}$, Joen Huussen ${ }^{2}$ and Stefan D. Plessis ${ }^{3}$ \\ ${ }^{I}$ Department of Basic Medical Sciences, College of Medicine, University of Malawi \\ ${ }^{2}$ Ans Arets, Avans University, Breda, The Netherlands \\ ${ }^{3}$ Division of Medical Physiology, University of Stellenbosch, Tygerberg, South Africa
}

\begin{abstract}
Nitric oxide (NO) is a signaling molecule produced by intracellular nitric oxide synthase (NOS) enzymes. Studies have shown that this free radical affect sperm capacitation, a maturation step preceding acrosome reaction. This study was aimed at investigating the effects of exogenously administered NO through its donor, sodium nitroprusside (SNP) has on human sperm motility, viability and apoptosis markers. Increased concentrations of SNP (10, 30, 50, $100 \mu \mathrm{M}$ ) were administered to human spermatozoa in the presence or absence of NO synthase inhibitor, N-nitro-Larginine methyl ester. Spermatozoa motility and viability were assessed at 60 and 90 minutes of incubation. The caspase activity was assessed after 90 minutes of incubation. SNP significantly decreased spermatozoa motility and viability in a dose and time dependent manner $(\mathrm{p}<0.05)$. The caspase activity was significantly increased with increasing concentration of SNP ( $<$ 0.05). This study therefore conclude that high concentrations of NO result in the decrease of sperm function and increase of germ cell apoptosis rate that may contribute to male infertility.
\end{abstract}

Keywords: Apoptosis, motility, nitric oxide, sodium nitroprusside, spermatozoa.

\section{INTRODUCTION}

Nitric oxide (NO) is one of the most widely studied molecules in the human body because of its (sometimes paradoxical) roles in several biological functions. It is a free radical gaseous molecule with a very short biological halflife [1]. NO is generated by the family of NO synthase (NOS) enzymes, which catalyze the conversion of L-arginine to NO and L-citrulline [2] and has been shown to be expressed in human spermatozoa [3].

Recent information on the NO has proved its importance as an intercellular and intracellular messenger controlling many physiological processes. It is also a mediator of cytokines and growth factors in various cell types. It is expressed in response to inflammatory cytokines and lipopolysaccharides [4]. In vitro studies have investigated the effects of exogenous NO donors on sperm motility and viability with controversial results [5-9]. Low concentration of NO increased the motility and viability of spermatozoa. However, high concentration of NO decreased the sperm motility and viability [10]. The bimodal motility response to various concentrations of $\mathrm{NO}$ releasing compounds could be due to dual nature of $\mathrm{NO}$, as both a transduction molecule at low concentration and a cytotoxic effector at high concentrations in systems $[6,7]$. However, the role of $\mathrm{NO}$ on

*Address correspondence to this author at the Department of Basic Medical Sciences, College of Medicine, University of Malawi, P/Bag 360, Chichiri, Blantyre 3; Tel: +265 111 874107; Fax: +265 111872644 ;

E-mail: flampiao@medcol.mw human spermatozoa apoptosis is not yet clearly elucidated. The aim of this study was to investigate the role of $\mathrm{NO}$ on sperm function with specific reference to the effect it has on sperm apoptosis.

\section{MATERIALS AND METHODS}

\section{Chemicals}

Hams F10, sodium nitroprusside (SNP), N-nitro-Larginine methyl ester (L-NAME), and eosin-nigrosin were obtained from Sigma Chemical (St. Louis, MO, USA). Caspase-Glo ${ }^{\circledR}$ 3/7 assay kit was purchased from Promega, USA.

\section{Preparation of Semen Samples}

The 25 donors recruited in this study provided informed consent for a research protocol approved by the University of Stellenbosch Ethics Committee (Tygerberg, South Africa). Fresh semen samples were obtained by masturbation from healthy volunteers after a minimum of two days of sexual abstinence according to World Health Organization (WHO) guidelines [11]. Samples were left to liquefy $\left(37^{\circ} \mathrm{C}\right.$, $5 \% \mathrm{CO}_{2}$ ) for 30 minutes before processing. Motile sperm fractions were retrieved from the samples using a double wash $(400 \mathrm{x} \mathrm{g}, 5 \mathrm{~min})$ swim-up technique in Hams F10 medium containing $3 \%$ bovine serum albumin at room temperature $\left(25^{\circ} \mathrm{C}\right)$. After one hour, the supernatant containing motile sperm was collected and divided into aliquots. 
Table 1. Effects of sodium nitroprusside (SNP), in the absence or presence of N-nitro-L-arginine methyl ester (L-NAME) (0.7 mM) on human spermatozoa progressive motility, total motility, and viability after 60 and 90 minutes of incubation.

\begin{tabular}{|c|c|c|c|c|c|c|c|}
\hline & & Treatment & Control & $10 \mu \mathrm{M}$ & $30 \mu \mathrm{M}$ & $50 \mu \mathrm{M}$ & $100 \mu \mathrm{M}$ \\
\hline \multirow{4}{*}{$\begin{array}{l}\text { Progressive } \\
\text { Motility (\%) }\end{array}$} & \multirow[b]{2}{*}{$60 \mathrm{~min}$} & SNP & $36.6 \pm 2.6$ & $29.8 \pm 3.3$ & $27.9 \pm 3.3$ & $18.8 \pm 3.4^{*}$ & $16.5 \pm 2.5^{*}$ \\
\hline & & $\mathrm{SNP}+\mathrm{L}-\mathrm{N}$ & $35.3 \pm 2.4$ & $28.9 \pm 2.5$ & $28.1 \pm 2.2$ & $17.8 \pm 2.6 \#$ & $13.8 \pm 2.0 \#$ \\
\hline & \multirow[b]{2}{*}{$90 \mathrm{~min}$} & SNP & $33.8 \pm 2.6$ & $27.2 \pm 3.2$ & $16.8 \pm 2.6^{*}$ & $14.9 \pm 2.3^{*}$ & $8.4 \pm 1.8^{*}$ \\
\hline & & $\mathrm{SNP}+\mathrm{L}-\mathrm{N}$ & $33.8 \pm 3.6$ & $25.8 \pm 2.8$ & $13.9 \pm 2.5 \#$ & $12.5 \pm 2.4 \#$ & $8.0 \pm 2.2 \#$ \\
\hline \multirow{4}{*}{$\begin{array}{c}\text { Total Motility } \\
(\%)\end{array}$} & \multirow[b]{2}{*}{$60 \mathrm{~min}$} & SNP & $73.2 \pm 2.8$ & $66.4 \pm 2.5$ & $67.2 \pm 3.8$ & $53.1 \pm 4.0^{*}$ & $47.9 \pm 3.6^{*}$ \\
\hline & & $\mathrm{SNP}+\mathrm{L}-\mathrm{N}$ & $73.4 \pm 3.5$ & $66.9 \pm 3.6$ & $67.0 \pm 2.6$ & $61.7 \pm 4.1$ & $52.1 \pm 3.6 \#$ \\
\hline & \multirow[b]{2}{*}{$90 \mathrm{~min}$} & SNP & $67.6 \pm 3.7$ & $64.2 \pm 2.8$ & $52.4 \pm 3.6$ & $51.1 \pm 3.7$ & $50.5 \pm 2.8$ \\
\hline & & $\mathrm{SNP}+\mathrm{L}-\mathrm{N}$ & $72.4 \pm 2.8$ & $63.1 \pm 2.1$ & $46.9 \pm 3.4 \#$ & $49.1 \pm 3.8 \#$ & $47.0 \pm 3.4 \#$ \\
\hline \multirow{4}{*}{ Viability (\%) } & \multirow[b]{2}{*}{$60 \mathrm{~min}$} & SNP & $57.7 \pm 1.5$ & $56.2 \pm 2.5$ & $58.1 \pm 2.4$ & $52.6 \pm 2.2$ & $49.9 \pm 2.0$ \\
\hline & & $\mathrm{SNP}+\mathrm{L}-\mathrm{N}$ & $65.9 \pm 2.1$ & $50.0 \pm 2.6$ & $50.3 \pm 2.6 \#$ & $47.1 \pm 1.6 \#$ & $43.0 \pm 2.5$ \\
\hline & \multirow[b]{2}{*}{$90 \mathrm{~min}$} & SNP & $52.7 \pm 2.4$ & $53.6 \pm 1.7$ & $46.4 \pm 2.1$ & $39.5 \pm 1.9^{*}$ & $37.2 \pm 1.3^{*}$ \\
\hline & & $\mathrm{SNP}+\mathrm{L}-\mathrm{N}$ & $50.3 \pm 2.0$ & $51.1 \pm 1.5$ & $43.7 \pm 1.6$ & $37.6 \pm 1.5 \#$ & $33.9 \pm 1.9$ \\
\hline
\end{tabular}

$* \mathrm{P}<0.05$ vs. Control SNP; \#P $<0.05$ vs. Control SNP + L-N

\section{Experimental Procedure}

The first group of aliquots were treated with increasing concentrations of SNP $(10,30,50,100 \mu \mathrm{M})$ except for the control. The second group was treated with similar increasing concentrations of SNP plus NOS inhibitor (L-NAME, $0.7 \mathrm{mM}$ ) except for the control.

\section{Motility Parameters}

Motility was measured by means of computer aided semen analysis (Sperm Class Analyzer, Microptic, Spain). The motility parameters of interest were total motility and progressive motility. Motility parameters were measured after 60 and 90 minutes of incubation.

\section{Cell Viability}

Control and treated sample drops were placed on glass slides and mixed with eosin-nigrosin dye. Smears were made on the slides and left to air-dry. Spermatozoa with impaired metabolism or damaged membranes will allow the eosinnigrosin dye to enter the cell and stain the DNA. The slides were observed under a light microscope and at least 200 cells were evaluated on each slide.

\section{Caspase Activity}

Caspase was used as the marker for apoptosis. The assay was done according to the manufacturer's instruction. Briefly, about 1 million sperm cells were rinsed with binding buffer. The cells were then resuspended in $200 \mu \mathrm{l}$ of binding buffer. $5 \mu$ of Caspase-Glo ${ }^{\circledR} 3 / 7$ was added to the cells before transferring them into a 96 well microplate. The cells were incubated at room temperature for 5-15 minutes in the dark before luminescence was measured by the GloMax ${ }^{\circledR}$
Multi-detection System (Promega, USA). Caspase levels were expressed as relative luminescence units (RLU).

\section{Statistical Analysis}

The results were analyzed on the Prism 4 statistical program (GraphPad, San Diego, CA, USA). All data are expressed as mean \pm SEM. One-way ANOVA (with Bonferroni post hoc test if $\mathrm{P}<0.05$ ) was used for statistical analysis. Differences were regarded statistically significant if $\mathrm{P}<0.05$.

\section{RESULTS}

\section{Sperm Motility}

After 60 minutes of incubation, progressive motility significantly decreased with $50 \mu \mathrm{M}$ SNP compared to the SNP control, $100 \mu \mathrm{M}$ SNP compared to the SNP control, $50 \mu \mathrm{M}$ SNP + $0.7 \mathrm{mM}$ L-NAME compared to the L-NAME control and $100 \mu \mathrm{M}$ SNP + $0.7 \mathrm{mM}$ L-NAME compared to the L-NAME control as shown in Table $\mathbf{1 .}$

After 90 minutes of incubation, progressive motility significantly decreased with $30 \mu \mathrm{M}$ SNP compared to the SNP control, $50 \mu \mathrm{M}$ SNP compared to the SNP control, $100 \mu \mathrm{M}$ SNP compared to the SNP control, $30 \mu \mathrm{M}$ SNP + $0.7 \mathrm{mM}$ L-NAME compared to the L-NAME control, $50 \mu \mathrm{M}$ SNP + $0.7 \mathrm{mM}$ L-NAME compared to the L-NAME control and $100 \mu \mathrm{M}$ SNP $+0.7 \mathrm{mM}$ L-NAME compared to the L-NAME control as shown in Table 1.

After 60 minutes of incubation, total motility significantly decreased with $50 \mu \mathrm{M}$ SNP compared to the SNP control, $100 \mu \mathrm{M}$ SNP compared to the SNP control, $100 \mu \mathrm{M}$ SNP + $0.7 \mathrm{mM}$ L-NAME compared to the L-NAME control as shown in Table $\mathbf{1}$. 


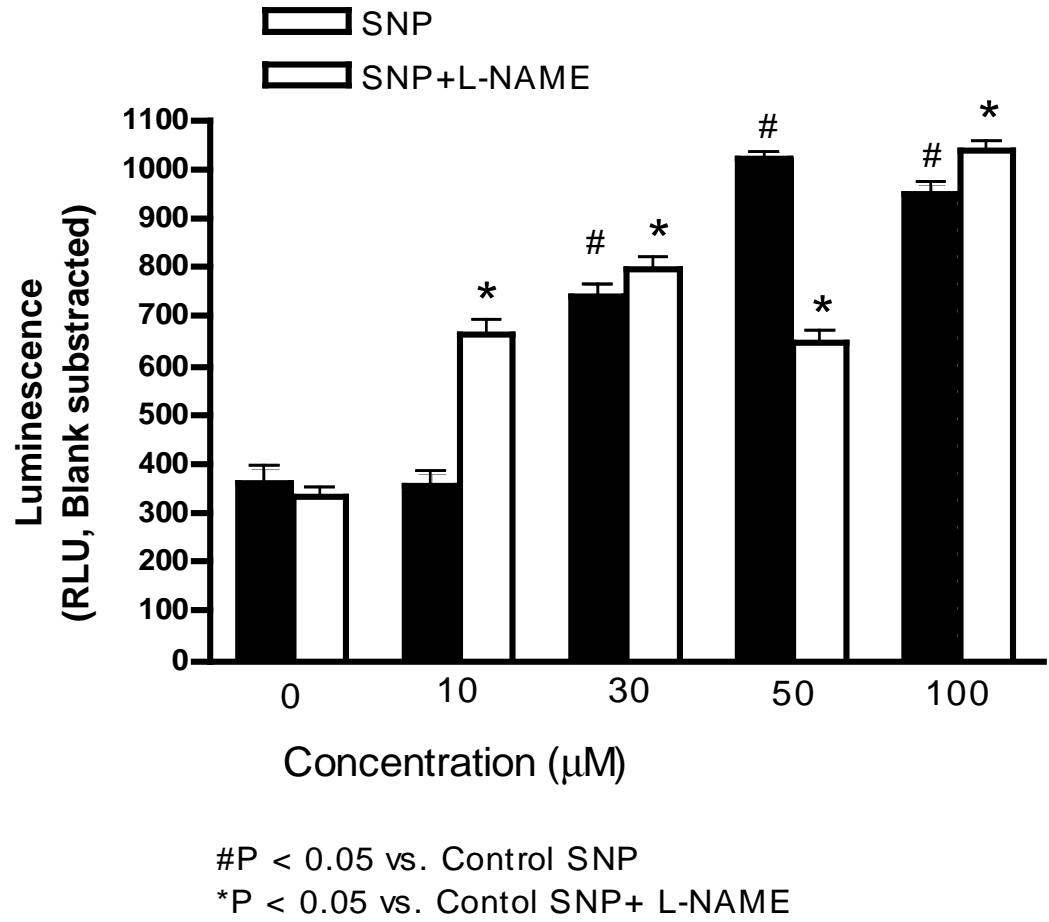

Fig. (1). Effects of SNP on caspase activity of human spermatozoa in the presence or absence of L-NAME.

After 90 minutes of incubation, total motility significantly decreased with $30 \mu \mathrm{M} \mathrm{SNP}+0.7 \mathrm{mM}$ L-NAME compared to the L-NAME control, $50 \mu \mathrm{M}$ SNP + $0.7 \mathrm{mM}$ L-NAME compared to the L-NAME control and $100 \mu \mathrm{M}$ SNP + $0.7 \mathrm{mM}$ L-NAME compared to the L-NAME control as shown in Table $\mathbf{1}$.

\section{Sperm Viability}

After 60 minutes of incubation, viable cells significantly decreased with $30 \mu \mathrm{M} \mathrm{SNP}+0.7 \mathrm{mM}$ L-NAME compared to the L-NAME control, $50 \mu \mathrm{M}$ SNP $+0.7 \mathrm{mM}$ L-NAME compared to the L-NAME control and $100 \mu \mathrm{M}$ SNP + $0.7 \mathrm{mM}$ L-NAME compared to the L-NAME control as shown in Table 1.

After 90 minutes of incubation, viable cells significantly decreased with $50 \mu \mathrm{M}$ SNP compared to the SNP control, $100 \mu \mathrm{M}$ SNP compared to the SNP control, $50 \mu \mathrm{M}$ SNP + $0.7 \mathrm{mM}$ L-NAME compared to the L-NAME control and $100 \mu \mathrm{M}$ SNP + $0.7 \mathrm{mM}$ L-NAME compared to the L-NAME control as shown in Table $\mathbf{1}$.

\section{Sperm Apoptosis}

We observed a significant increase of caspase activity with the administration of SNP from the concentration of $30 \mu \mathrm{M}$ in a dose dependent manner. Similarly, the addition of SNP and L-NAME also significantly increased the caspase activity in a dose dependent manner (Fig. 1).

\section{DISCUSSION}

Nitric oxide is reported to play an important role in sperm function at physiological concentration [10, 12]. It is a free radical involved in the intra- and intercellular signaling mechanisms. Nitric oxide is generated from the oxidation of L-arginine to L-citrulline by 3 isoforms of NADPHdependent NO/NOS [13]. Two constitutive $\mathrm{Ca}^{2+}$-dependent isoforms are known, i.e. neuronal or brain NOS (n/bNOS) firstly found in neurons and endothelial NOS (eNOS) firstly found in endothelial cells [14]. In addition, one inducible $\mathrm{Ca}^{2+}$-independent isoform (iNOS) has been also described [15], firstly identified in macrophages. The positive effects of NO are shown in physiologic processes such as sperm capacitation [10]. The negative effects represent probably the role of $\mathrm{NO}$ as an inflammatory mediator in response to chronic or subclinical infection [1]. NO can have pathological effects and result in decreased sperm function through the production of peroxynitrate $\left(\mathrm{ONOO}^{-}\right)$. Several data suggest a relevant role of NO in sperm cell physiology [16-18], but conclusive data on its role in spermatozoa are still lacking. This study has used an exogenous NO donor, SNP. Under physiological conditions, human spermatozoa are capable of producing NO since they have NOS which is responsible for the conversion of 1 -arginine to $\mathrm{NO}$ and 1-citrulline [2].

In this study we have found a decrease in sperm motility parameters in a dose and time dependent manner. This is in agreement with the findings of other studies [16-20]. In some studies NO has been shown to exert positive effects on sperm motility parameters at lower concentrations [5, 9]. However, in this study we did not observe an improvement of sperm motility parameters at the lowest NO concentration administered $(10 \mu \mathrm{M})$.

Our viability studies have shown that NO leads to a decrease in sperm viability in a dose and time dependent 
manner. This is in agreement with findings of other studies $[6,21]$. In a previous study $\mathrm{NO}$ has been shown to exert positive effects on sperm viability [9]. However, in this study we did not observe an improvement of sperm viability.

As far as we are concerned this is the first study to report that incubation of human spermatozoa in the presence of SNP induces an increase in caspase activity in human spermatozoa. A similar finding was reported by Moran et al. [20] in which SNP dramatically increased the caspase activity in boar spermatozoa. A previous study also reported that the concentration of NO is positively correlated with the apoptotic rate of sperm cells in infertile men [21]. They reported that the amount of NO in semen from infertile men had a close relationship with apoptotic rate of sperm cells [21]. We therefore speculate that high concentration of NO may result in the increase of sperm cell apoptosis rate and lead to male infertility.

\section{CONFLICT OF INTEREST}

The authors confirm that this article content has no conflict of interest.

\section{ACKNOWLEDGEMENTS}

Declared none.

\section{REFERENCES}

[1] Santoro G, Romeo C, Impellizzeri P, Lentile R, Cuntroneo G, Trimarchi F. Nitric oxide synthase patterns in normal and varicocele testis in adolescents. BJU Int 2001; 88: 967-3.

[2] O’Bryan MK, Zini A, Cheng CY, Schlegel PN. Human sperm endothelial nitric oxide synthase expression: correlation with sperm motility. Fertil Steril 1998; 70: 1143-7.

[3] Lewis SEM, Donnelly ET, Sterling ESL, Kennedy MS, Thompson W, Chakravarthy U. Nitric oxide synthase and nitrite production in human spermatozoa: evidence that endogenous nitric oxide is beneficial to sperm motility. Mol Hum Reprod 1996; 2: 873-8.

[4] Loganathasamy K. Nitric oxide: a double adged weapon for sperm functions. J Vet Sci Technol 2012; 3: 6.
[5] Hellstrom WJG, Bell M, Wang R, Sikka SC. Effects of sodium nitroprusside on sperm motility, viability and lipid peroxidation. Fertil Steril 1994; 61: 1117-2.

[6] Rosselli M, Dubey RK, Imthurn B, Macas E, Keller PJ. Effects of nitric oxide on human spermatozoa: evidence that nitric oxide decreases sperm motility and induces sperm toxicity. Hum Reprod 1995; 10: 1786-90.

[7] Weinberg JB, Doty E, Bavaventena J, Haney JF. Nitric oxide inhibition of sperm motility. Fertil Steril 1995; 64: 408-3.

[8] Nobunaga T, Tokugawa Y, Hashimoto K. Elevated nitric oxide concentration in the seminal plasma of infertile males: NO inhibits sperm motility. Am J Reprod Immunol 1996; 36: 193-7.

[9] Zhang H, Zheng RL. Possible role of nitric oxide on fertile and astheozoospermic infertile human sperm functions. Free Radic Res 1996; 25: 347-54.

[10] Aquila S, Giordano F, Guido C, Rago V, Carpino A. Insulin affects sperm capacitation in pig through nitric oxide. Asian $\mathrm{J}$ Androl 2013; $15: 835-7$.

[11] World Health Organization. WHO Manual for the Examination of Human Semen and Sperm-cervical Mucus Interaction. $4^{\text {th }}$ ed. Cambridge University Press 1990.

[12] Balercia G, Moretti S, Vignini A, et al. Role of nitric oxide concentrations on human sperm motility. J Androl 2004; 25: 245-9.

[13] Palmer RM, Ashton DS, Moncada S. Vascular endothelial cells synthesize nitric oxide from L-arginine. Nature 1988; 333: 664-6.

[14] Knowles RG, Moncada S: Nitric oxide synthases in mammals. Biochem J 1994; 298: 249-58.

[15] Förstermann U, Closs EI, Pollock JS, et al. Nitric oxide synthase isozymes. Characterization, purification, molecular cloning, and functions. Hypertension 1994; 23:1121-31.

[16] Aquila S, Giordano F, Guido C, Rago V, Carpino A. Nitric oxide involvement in the acrosome reaction triggered by leptin in pig sperm. Reprod Biol Endocrinol 2011; 9: 133.

[17] Harrison RA, Gadella BM. Bicarbonate-induced membrane processing in sperm capacitation. Theriogenology 2005; 63: 34251.

[18] Amiri I, Karimi J, Piri H, et al. Association between nitric oxide and 8-hydroxydeoxyguanosine levels in semen of diabetic men. Syst Biol Reprod Med 2011; 57: 292-5.

[19] Moran JM, Madejón L, Ortega Ferrusola C, Peña FJ. Nitric oxide induces caspase activity in boar spermatozoa. Theriogenology 2008; 70: 91-6.

[20] Kameshwari DB, Siva AB, Shivaji S. Inhibition of in vitro capacitation of hamster spermatozoa by nitric oxide synthase inhibitors. Cell Mol Biol 2003; 49: 421-8.

[21] Sengoku K, Tamate K, Yashida T, Takaoka Y, Miyamoto T, Ishikawa M. Effects of low concentrations of nitric oxide on zona pellucida binding ability of human spermatozoa. Fertil Steril 1998; 69: 522-7. 